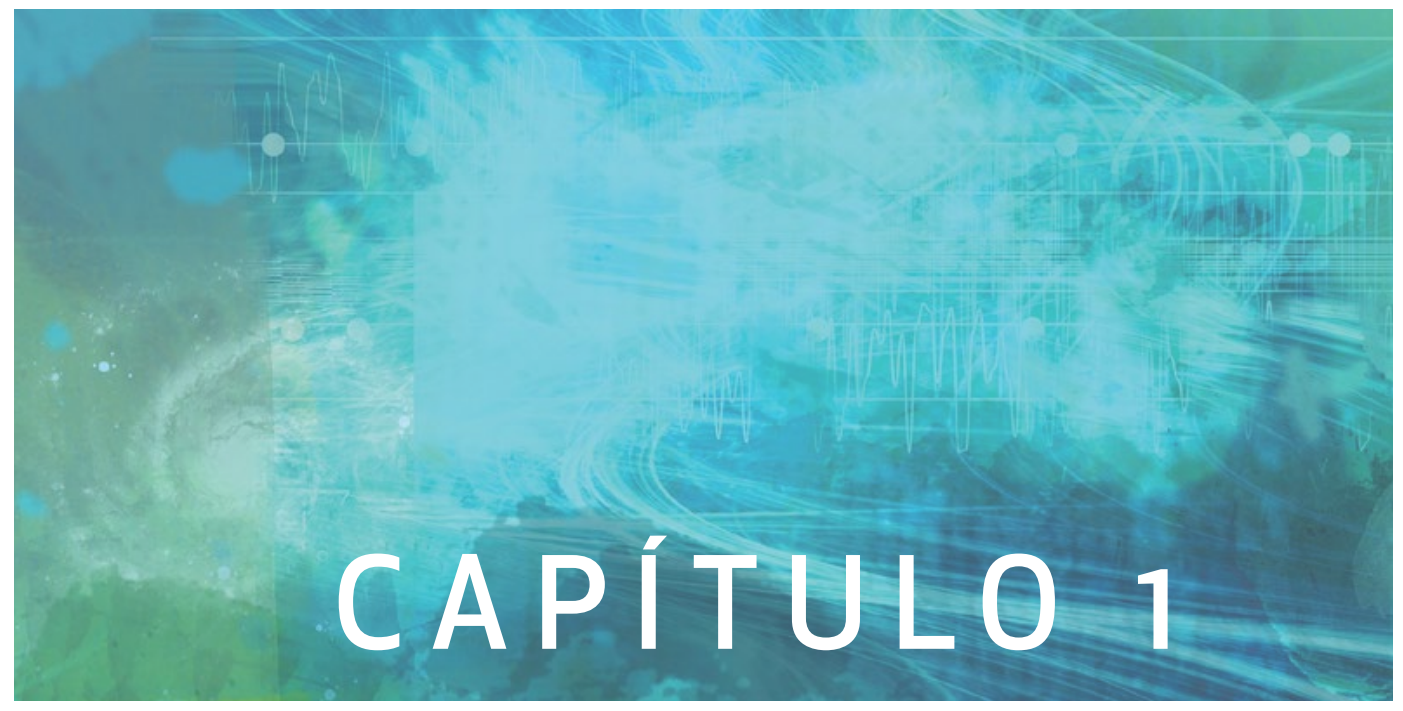





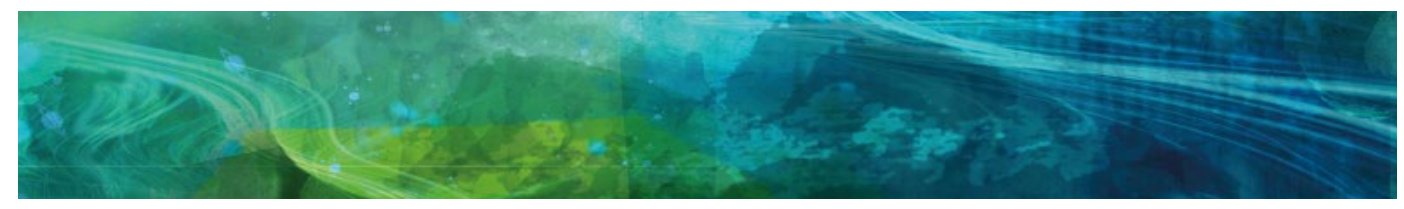

\title{
Las zonas francas: su evolución e importancia para la economía
}

\author{
José Ever Castellanos Narciso' \\ Fabio Fernando Moscoso Durán²
}

1 Docente de la UNAD, sede Bogotá, Colombia. Doctor en Gestión de la Universidad EAN, Colombia. Doctor en Ciencias Empresariales de la Universidad de Nebrija, España. Magister en Administración, Especialista en Gerencia Estratégica de Mercadeo, Administrador de Empresas. Correo electrónico: jose.castellanos@unad.edu.co

$2 \mathrm{PhD}$ en Ciencias Políticas de la Universidad de Fribourg, Suiza. Docente de la Facultad de Finanzas y Ciencias Económicas de la Universidad EAN, Bogotá, Colombia. Correo electrónico: ffmoscoso@universidadean.edu.co Tel.: (+571)3108559720 


\section{Resumen}

Objeto: este capítulo tiene como objetivo principal analizar la evolución histórica y la importancia de las zonas francas para la economía nacional y mundial. En primera instancia se da a conocer el surgimiento de estas organizaciones a lo largo del tiempo y el papel que juegan en las principales regiones geográficas a las que pertenecen. Posteriormente se describe la importancia de las zonas francas para Colombia y el rol que cumplen en el comercio internacional. Por último, se detallan los principales hallazgos y las conclusiones.

Diseño metodológico: el capítulo ha sido elaborado a partir de la revisión bibliográfica de los principales trabajos de investigación, papers, libros, autores y entidades que tienen que ver con la temática; además se indagaron las principales fuentes secundarias que tienen relación directa con datos estadísticos de las zonas francas como el DANE y el Banco Mundial, entre otros. De igual forma, se tomaron como referentes los autores más representativos para dar a conocer los aportes realizados y su nivel de importancia.

Aportaciones y resultados: el presente documento refleja una sucinta explicación y análisis de las principales investigaciones sobre la evolución histórica y la importancia que tienen para las regiones estas organizaciones, tanto en el ámbito nacional, como en el mundial.

Valor añadido: con esta investigación se espera brindar un apoyo conceptual a la toma de decisiones empresariales y con ello generar nuevo conocimiento sobre la temática para futuras investigaciones.

Palabras clave: zonas francas, parques industriales, zonas económicas especiales. 


\section{Introducción}

Actualmente las organizaciones son muy conscientes del papel que la competitividad juega en su futuro, pues se traduce en ventaja competitiva para la empresa (Igartua, 2009). Con una visión más amplia y visto desde el escenario del Ranking del "The Global Competitiveness Report", del Foro Económico Mundial (2017-2018, p. 13) y (2016-2017), Colombia quedó en el puesto 66 de 137 países, con un puntaje de 4,29, superado por Chile que quedó en el puesto 33 con 4,71; Costa Rica en el puesto 47 con 4,50; Panamá en el puesto 50 con 4,44 y México en el puesto 51 con 4,41. El primer puesto lo ocupó Suiza con 5,86 (tabla 1).

A partir de estos datos, se observa que Colombia perdió 5 posiciones, si se compara con las cifras del 2016 y 2017, pasando del puesto 61 al 66 a nivel mundial. Esta situación es preocupante si se tiene en cuenta que el país tiene la meta de ser uno de los tres más innovadores de Latinoamérica para el 2025; en virtud de lo cual, esta visión se encuentra plasmada en los documentos CONPES, el Plan Nacional de Desarrollo 2014-2018 y descrita por el Comité Técnico Mixto de Innovación del Sistema Nacional de Competitividad, Ciencia, Tecnología e Innovación. Si no se implementa en las organizaciones empresariales una cultura que lleve a fomentar un sistema que fomente la competitividad, no se generará creatividad e innovación al interior de las mismas, y, por lo tanto, no se desarrollarán las ventajas competitivas que llevarán a la sostenibilidad y sustentabilidad organizacional. 
Tabla 1. Ranking de competitividad de algunos países del mundo

\begin{tabular}{|c|c|c|c|c|c|c|}
\hline$\frac{n}{10}$ & $\frac{5}{\frac{0}{8}}$ & 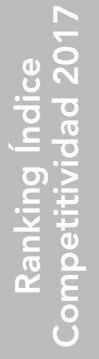 & $\begin{array}{l}\frac{w}{\alpha} \\
\mathcal{O} \\
u\end{array}$ & 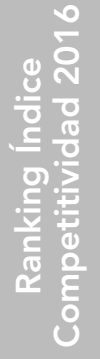 & 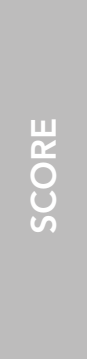 & 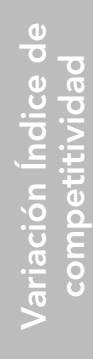 \\
\hline Suiza & Europa & 1 & 5.86 & 1 & 5.81 & 0 \\
\hline EEUU & Norte América & 2 & 5.85 & 3 & 5.70 & 1 \\
\hline Singapur & Asia Pacífico & 3 & 5.71 & 2 & 5.72 & -1 \\
\hline Países Bajos & Europa & 4 & 5.66 & 4 & 5.57 & 0 \\
\hline Japón & Asia Pacífico & 9 & 5.49 & 8 & 5.48 & -1 \\
\hline Canadá & Norte América & 14 & 5.35 & 15 & 5.27 & 1 \\
\hline Emiratos Árabes Unidos & Este medio y norte de África & 17 & 5.30 & 16 & 5.26 & -1 \\
\hline Qatar & Este medio y norte de África & 25 & 5.11 & 18 & 5.23 & -7 \\
\hline Chile & Latinoamérica y el Caribe & 33 & 4.71 & 33 & 4.64 & 0 \\
\hline Azerbajian & Eurasia & 35 & 4.69 & 37 & 4.55 & 2 \\
\hline India & Sur de Asia & 40 & 4.59 & 39 & 4.52 & -1 \\
\hline Costa Rica & Latinoamérica y el Caribe & 47 & 4.50 & 54 & 4.41 & 7 \\
\hline Panamá & Latinoamérica y el Caribe & 50 & 4.44 & 42 & 4.51 & -8 \\
\hline México & Latinoamérica y el Caribe & 51 & 4.44 & 51 & 4.41 & 0 \\
\hline Colombia & Latinoamérica y el Caribe & 66 & 4.29 & 61 & 4.30 & -5 \\
\hline Jamaica & Latinoamérica y el Caribe & 70 & 4.25 & 75 & 4.13 & 5 \\
\hline Perú & Latinoamérica y el Caribe & 72 & 4.22 & 67 & 4.23 & -5 \\
\hline Uruguay & Latinoamérica y el Caribe & 76 & 4.15 & 73 & 4.17 & -3 \\
\hline
\end{tabular}

Fuente: Elaboración propia con base en Schwab (2017).

La situación descrita refleja la importancia que tienen las zonas francas para la economía nacional, más aún si se articulan con el Plan Nacional de Desarrollo 2014-2018, al ser entes responsables de dar cumplimento a la estrategia de "incrementar la productividad de las empresas colombianas a partir de la sofisticación y diversificación del aparato productivo", y ser responsables directas 
de "internacionalizar los sectores productivos de bienes y servicios" con el fin de aumentar las exportaciones del país.

En ese orden de ideas, el gobierno centró su atención en las zonas francas, al exponer que las mismas deben "fortalecer la competitividad". La meta se cumple si las zonas francas se convierten en aquel puente entre organizaciones y regiones que permiten fomentar las exportaciones. Además, hay que tener en cuenta que la visión a largo plazo de Colombia está centrada en los años 2025 y 2032. El objetivo a 2025 está plasmado en ser uno de los tres países más innovadores de la región, como se describió anteriormente. De la misma manera, se propone ser uno de los tres países más competitivos en América Latina para el año 2032. Esta visión fue desarrollada por la Comisión Nacional de Competitividad, creada por el gobierno nacional en el año 2006 y cuenta con la participación directa del gobierno, empresarios, trabajadores, regiones, universidades y gremios:

En 2032 Colombia será uno de los tres países más competitivos de América Latina y tendrá un elevado nivel de ingreso por persona equivalente al de un país de ingresos medios altos, a través de una economía exportadora de bienes y servicios de alto valor agregado e innovación, con un ambiente de negocios que incentive la inversión local y extranjera, propicie la convergencia regional, mejore las oportunidades de empleo formal, eleve la calidad de vida y reduzca sustancialmente los niveles de pobreza. (Consejo Privado de Competitividad, 2007 p. 12).

En virtud de lo anterior, esta investigación tiene especial trascendencia para la economía nacional, para cuyos efectos se ha planteado la siguiente estructura: en la primera parte se analiza la evolución de las Zonas Francas (ZF), también llamadas en otras culturas Zonas Económicas Especiales (ZEE), donde se hace un análisis sobre los principales nombres que las mismas poseen y los diferentes objetivos que persiguen en el comercio internacional, según las necesidades de las regiones. La segunda parte menciona la importancia de estas organizaciones para América Latina y el Caribe, haciendo énfasis en Colombia. Finalmente, se habla sobre los principales hallazgos y conclusiones a los cuales 
se llegó después de haber consultados fuentes secundarias importantes como el Banco Mundial, el DANE, ANDI y Farole, entre otros.

\section{Marco teórico}

\section{Las zonas francas en la economía mundial}

Según Gaitán (2008), las zonas francas no nacen en el mundo moderno, sino que tienen sus raíces aproximadamente en el año 1300 A.C, cuando fenicios y romanos implementaron el sistema de otorgar algunos beneficios aduaneros y de impuestos para impulsar sus rutas de navegación, practicar el comercio y fomentar sus exportaciones en puertos como Biblos, Akka, Sidon, Arados, Leptis, Portus y Ostia, entre otros, obteniendo como consecuencia el pleno dominio del mar Mediterráneo. Para FIAS (2008), en la época de la colonia las denominadas zonas de libre comercio toman especial importancia, debido a que los países dominantes buscaban incrementar su poder, lo que fomentó el surgimiento de importantes puertos comerciales como Gibraltar (1704), Singapur (1819), Hong Kong (1842), Hamburgo (1888) y Copenhagen (1891).

De esta forma se puede considerar a las Zonas Económicas Especiales (ZEE) como aquellas "áreas geográficas delimitadas dentro de las fronteras nacionales de un país donde las reglas de los negocios son diferentes, generalmente más liberales que aquellas que prevalecen en el territorio nacional" (Informe del Banco Mundial, 2012, p. 3.); y que, además, su modelo les permite funcionar como herramienta eficaz en el comercio, la política industrial y la inversión. Por lo tanto luchan para erradicar las barreras que encuentran en el sistema económico, tales como: políticas restrictivas, falta de gobernabilidad, infraestructura inadecuada y problemas de acceso a la propiedad. Cabe mencionar que el concepto de zona económica especial hace referencia a las mismas zonas francas a nivel internacional, por lo tanto, este es un concepto genérico que incluye las mismas zonas, que a su vez sirven como parte del objeto de estudio en este trabajo de investigación, aunque en cada región del mundo puede adoptar diferentes nombres (tabla 2). 
Tabla 2. Zonas económicas especiales

\begin{tabular}{ll}
\hline \multicolumn{1}{c}{ Condiciones } & \multicolumn{1}{c}{ Países } \\
Maquiladoras/maquiladora (empresas entrantes) & $\begin{array}{l}\text { Costa Rica, El Salvador, Guatemala, } \\
\text { Honduras, México, Panamá }\end{array}$ \\
\hline Zonas Francas (Free Zones) & $\begin{array}{l}\text { Costa Rica, Honduras, Irlanda, Trinidad } \\
\text { y Tobago, Turquía, Emiratos Árabes } \\
\text { Unidos, Uruguay, Venezuela }\end{array}$ \\
\hline Zonas Económicas Especiales & China \\
\hline Zonas Industriales Libres & Colombia \\
\hline Zonas Industriales Libres de Bienes y Servicios & Bulgaria, Chile \\
\hline Zonas Francas (Free trade zones) & Jamaica \\
\hline Zonas Francas de Exportación & República Islámica de Irán \\
\hline Zonas Especiales para la Exportación & Filipinas \\
\hline Zonas Francas de Procesamiento para la Exportación & Togo \\
\hline Fábricas Libres de Impuestos & Fiji \\
\hline Zona Enlazada & Indonesia \\
\hline Zonas Francas y Zonas de Procesamiento Especial & Perú \\
\hline Zonas Económicas Libres & Federación Rusa \\
\hline Propiedades Industriales & Tailandia \\
\hline Puntos Francos (Zonas Francas Industriales Especiales) & Camerún \\
\hline
\end{tabular}

Fuente: Céspedes-Torres (2016), con base en Blanco y Sadni (2002, p. 78).

A lo largo de los años, el concepto de zona económica especial ha evolucionado, dando lugar a varias clasificaciones. Estas han sido objeto de estudio por parte de diferentes autores y entidades, entre los que se destacan el Banco Mundial (2012), Pakdeenurit, Suthikarnnarunai y Rattanawong (2014) y Arteaga, et al. (2016). A continuación se resumen los principales postulados de estas definiciones:

a). Zonas francas o de libre comercio (free trade zones): generalmente están cercadas y su delimitación física es pequeña, se dedican al almacenamiento y depósito de mercancías, además de facilitar la distribución comercial para el trasbordo y reexportación de bienes. No están dedicadas a las actividades de transformación de materias primas y se encuentran en los puertos de entrada de todo el mundo como Colón en Panamá y las zonas francas de España. 


\section{b). Zonas francas Industriales dedicadas a la exportación} (export processing zones): su misión se centra en transformar la materia prima para su posterior exportación. Este modelo se subdivide en dos: las tradicionales, que están exclusivamente dedicadas a la transformación y exportación de sus productos; y el modelo híbrido, que maneja todas aquellas industrias dedicadas a la exportación o no exportación. Dentro de este modelo también se encuentran las zonas separadas que manejan las organizaciones registradas como "orientadas a la exportación".

c). Puertos francos (free ports): su territorio físico es muy amplio y se destina a muchas actividades, entre las que se encuentra el servicio turístico y las ventas al por menor; en estas zonas pueden haber incluso residentes. Un ejemplo propio de ello son los puertos a gran escala de China.

d). Zonas de empresas (enterprise zones): la mayoría de organizaciones de este modelo están en los países desarrollados como Francia, Estados Unidos e Inglaterra. Su objetivo es ayudar a aquellas zonas urbanas o rurales que tienen problemas de desarrollo, para cuyos efectos inyectan incentivos fiscales y subvenciones financieras a estos proyectos.

e). Fábricas individuales orientadas a la exportación (single factory): el modelo ofrece incentivos y privilegios a las organizaciones dedicadas a exportar, independientemente de su ubicación geográfica. Sus principales ejemplos son Islas Mauricio, México, Fiji y Madagascar. Cabe mencionar que muchas economías del mundo permiten los dos modelos, es decir, las que tienen una zona definida y las organizaciones single factory, como por ejemplo Estados Unidos, Sr Lanka y Costa Rica.

f). Zonas especializadas (specialized zones): los proyectos se caracterizan porque en cada zona se posee un objetivo específico de polo de desarrollo, perteneciente a un solo sector, como por ejemplo los parques científicos y tecnológicos, áreas financieras, zonas de logística y mantenimiento, las zonas de juego o las zonas petroquímicas. 
Para el FIAS (2008) y el Banco Mundial (2012), las zonas económicas se pueden dividir de muchas maneras, dependiendo del propósito que estas persigan (tabla 3). Sin embargo, vale la pena aclarar que los parques industriales que están incluidos en la tabla 3, normalmente no son considerados como una zona económica porque estos operan sin régimen especial de aduana, régimen regulatorio o régimen fiscal.

Tabla 3. Resumen de las diferentes zonas económicas

\begin{tabular}{|c|c|c|c|c|c|c|}
\hline Tipo & $\frac{1}{\frac{10}{0}} \frac{1}{0}>$ & $\frac{2}{\frac{2}{10}} \frac{8}{\frac{3}{10}}$ & Ubicación & $\begin{array}{l}\text { Actividades } \\
\text { elegibles }\end{array}$ & Mercado & Ejemplo \\
\hline $\begin{array}{l}\text { Parques } \\
\text { industriales }\end{array}$ & 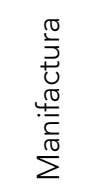 & 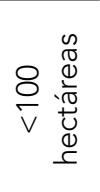 & Diversa & $\begin{array}{l}\text { Mayoritariamente } \\
\text { manufacturera }\end{array}$ & $\begin{array}{l}\text { Nacional, } \\
\text { exportación }\end{array}$ & $\begin{array}{l}\text { Existe en la } \\
\text { mayoría de } \\
\text { los países }\end{array}$ \\
\hline $\begin{array}{l}\text { Zona franca } \\
\text { comercial }\end{array}$ & 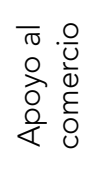 & 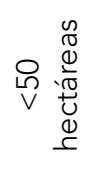 & $\begin{array}{l}\text { Puertos y } \\
\text { aeropuertos }\end{array}$ & $\begin{array}{c}\text { Relacionada } \\
\text { comercialmente } \\
\text { al procesamiento } \\
\text { y servicios }\end{array}$ & $\begin{array}{l}\text { Reexportació, } \\
\text { nacional }\end{array}$ & $\begin{array}{l}\text { Zona Libre } \\
\text { de Colon } \\
\text { Panamá }\end{array}$ \\
\hline $\begin{array}{l}\text { Zonas } \\
\text { franca de } \\
\text { exportación } \\
\text { (ZFE) }\end{array}$ & 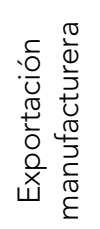 & 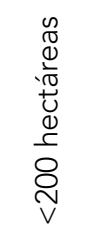 & $\begin{array}{l}\text { Puertos y } \\
\text { aeropuertos }\end{array}$ & $\begin{array}{l}\text { Mayoritariamente } \\
\text { manufacturera }\end{array}$ & Exportación & $\begin{array}{c}\text { Masan, } \\
\text { Corea, Rio } \\
\text { Athi, Kenia }\end{array}$ \\
\hline $\begin{array}{l}\text { Zonas de } \\
\text { empresas } \\
\text { libres (zonas } \\
\text { de "una sola } \\
\text { fabrica") }\end{array}$ & 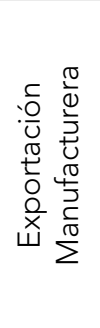 & 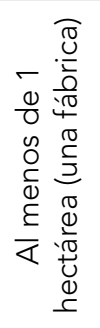 & Diversa & $\begin{array}{c}\text { Mayoritariamente } \\
\text { manufacturera }\end{array}$ & Exportación & $\begin{array}{l}\text { Mauricio, } \\
\text { México }\end{array}$ \\
\hline $\begin{array}{l}\text { Zona amplia } \\
\text { de ZEE y } \\
\text { puertos libres }\end{array}$ & 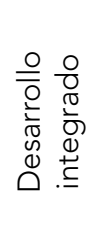 & 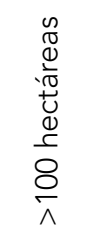 & Mixta & Multi-uso & $\begin{array}{l}\text { Nacional, } \\
\text { interno, } \\
\text { exportación }\end{array}$ & $\begin{array}{l}\text { Shenzhe, } \\
\text { China, } \\
\text { Agaba, } \\
\text { Jordania }\end{array}$ \\
\hline
\end{tabular}

Fuente: Banco Mundial (2012, p. 3), IFAS (2008). 


\section{Importancia de las zonas francas en la economía mundial}

Como lo describe The Economist (2015), cuando se creó la primera Zona Económica Especial (ZEE) moderna en el aeropuerto de Shannon, de Irlanda, en el año de 1959, el proyecto no tuvo el impacto esperado porque muy pocos países se interesaron. Hoy en día, la mayoría de economías del mundo cuentan con ZEE, principalmente por las ventajas que estas ofrecen como trámites aduaneros simplificados, incentivos fiscales y una mayor libertad para la importación y exportación de mercancías.

La Organización Internacional del Trabajo (OIT) examina la evolución de las ZEE mediante análisis estadísticos; por ejemplo, reporta, para el año 1986, la existencia de 176 ZEE, distribuidas en 47 países. En el 2006, la misma entidad vuelve a reportar 3500 zonas en 130 países del mundo (Boyenge, 2007). Según The Economist (2015), para el año 2014, a nivel mundial, la cantidad era de más de 4300 zonas, lo que significa un incremento del $4000 \%$, si se toma el dato desde 1975, año en el que solo había 79 a nivel mundial.

Así mismo, si se revisan las cifras del Banco Mundial en cuanto a generación de empleo, se puede apreciar que el impacto es muy positivo. Para el año 2007, la fuente señala que las ZEE empleaban de manera directa a más de 68 millones de personas en todo el mundo, de los cuales el $90 \%$ pertenece al continente asiático, tal y como se describe en la tabla 4. (Banco Mundial, 2008).

Tabla 4. Empleos directos generados por las ZEE a nivel mundial

\begin{tabular}{lll} 
Región & \multicolumn{2}{c}{$\begin{array}{c}\text { Empleo directo } \\
\text { (millones) }\end{array}$} \\
\hline En el mundo & 68.441 & $0,21 \%$ \\
\hline Asia y Pacífico & 61.089 & $2,30 \%$ \\
\hline América & 3.084 & $1,15 \%$ \\
\hline Europa Occidental & 0,179 & \\
\hline
\end{tabular}




\begin{tabular}{lcc}
\multicolumn{1}{c}{ Región } & \multicolumn{2}{c}{$\begin{array}{c}\text { Empleo directo } \\
\text { (millones) }\end{array}$} \\
\hline Europa del Este y Asia Central & 1.590 & $0,00 \%$ \\
\hline Oriente Medio y Norte de África & 1.498 & $1,59 \%$ \\
\hline África Subsahariana & 1.040 & $0,20 \%$ \\
\hline
\end{tabular}

Fuente: Arteaga et al. (2016).

Otros factores a tener en cuenta de los beneficios que representas las ZEE para la economía de los países son su Producto Interno Bruto (PIB), la inversión extranjera y las exportaciones. En las cifras de Zeng (2010), durante el 2007, las ZEE representaron el $22 \%$ del PIB nacional, el $46 \%$ de la inversión extranjera directa y el $60 \%$ de las exportaciones. En cuanto a importaciones y exportaciones, la cifra es muy representativa, si se mira por regiones (tabla 5), donde se describen cifras globales superando los 850.000 millones de dólares a nivel mundial (Banco mundial, 2008).

Tabla 5. Cantidad de exportaciones generada por las ZEE

\begin{tabular}{lll}
\hline Región & \multicolumn{1}{c}{$\begin{array}{c}\text { Empleo directo } \\
\text { (millones) }\end{array}$} & $\begin{array}{c}\text { Porcentaje } \\
\text { de empleo } \\
\text { nacional }\end{array}$ \\
\hline En el mundo & 851.032 & $40,80 \%$ \\
\hline Asia y Pacifico & 510.666 & $41,00 \%$ \\
\hline América & 72.636 & $39,00 \%$ \\
\hline Europa del Este y Asia central & 89.666 & $38,70 \%$ \\
\hline Oriente Medio y Norte de África & 169.469 & $36,40 \%$ \\
\hline África Subsahariana & 8.605 & $48,70 \%$ \\
\hline
\end{tabular}

Fuente: Arteaga et al. 2016

Con todo el potencial de crecimiento de las ZEE en el mundo, su éxito no ha sido del todo grandioso en todas las economías. Un ejemplo de pujanza, en la década de los ochentas, fueron las zonas establecidas al este de Asia que sirvieron como catalizador para las economías de los denominados "tigres asiáticos". Así mismo, un ejemplo de superación de las ZEE, durante los años noventa, lo constituye las economías de algunos países de América Latina. 
Aunque en algunas latitudes el éxito no ha sido tan importante, es de resaltar su importancia (Banco mundial, 2012). Arteaga y Martínez definen los principios que inspiran a las zonas francas de la siguiente manera:

- La promoción de las actividades del comercio exterior.

- La aplicación de formalidades aduaneras reducidas, en comparación con las requeridas en las demás partes del territorio aduanero comunitario.

- La reducción al mínimo de las medidas de control en el interior de dichas zonas y el ejercicio de las medidas de vigilancia en los límites exteriores.

- Dar cabida a todo tipo de mercancías, ya sean comunitarias o no comunitarias; habilitándose locales especiales para aquellas mercancías que supongan algún peligro o puedan alterar a otras.

- Dar cabida a cualquier tipo de actividad con las lógicas restricciones.

- Igualdad en las condiciones de utilización y consumo de las mercancías en las zonas francas con las previstas en cualquier otra parte del territorio aduanero comunitario, dada su condición de tal. (2003, p. 3.)

\section{Las zonas francas en la Unión Europea}

En la Unión Europea, las zonas francas constituyen un destino aduanero para almacenar mercancías comunitarias y no comunitarias, exentas de tributos como impuestos sobre el valor agregado IVA/IGIC, derechos de arancel, impuestos especiales y, en el caso de España, el impuesto general indirecto Canario, dependiendo de si las mercancías se despachan posteriormente a libre práctica o consumo (Arteaga, et al. , 2016). De acuerdo con Arteaga y Martínez (2003), el objetivo principal de las zonas francas europeas es el almacenaje de las mercancías para lograr diferir los impuestos y en algunas ocasiones lograr mejor planificación fiscal de la organización. 
Con base en lo anterior se puede considerar que las zonas francas de la Unión Europea juegan el papel de régimen aduanero. La situación anterior la describe Arteaga, et al. (2016), al citar el Código Aduanero de la Unión (CAU), aprobado por el Reglamento UE № 952/2013 del Parlamento Europeo y del Consejo del 9 de octubre de 2013, que en el considerando 49 establece: "En vista de mayores medidas de seguridad, es preciso que la inclusión de mercancías en una Zona Franca pase a convertirse en un régimen aduanero, y que tales mercancías se sujeten a controles aduaneros de entrada y a control de registros". Aunque, con el art. 158.1, estas mercancías no necesariamente deben disponer de una declaración aduanera por mantener la figura en la presentación de declaración aduanera como mercancías en el régimen de zona franca.

A partir del 1 de mayo de 2016, entra a regir el nuevo CAU que modifica la figura de destino aduanero de las zonas francas reconociendo únicamente como regímenes aduaneros el despacho a libre práctica, los regímenes especiales y la exportación. En la actualidad, se distinguen cuatro regímenes especiales divididos en: a) el transito interno y externo, b) el depósito aduanero y las zonas francas, c) los destinos especiales como importación temporal y destino final, d) el perfeccionamiento activo y pasivo (Arteaga, et al., 2016). La comparación del Código Aduanero Comunitario (CAC) que estaba en vigor hasta el 30 de abril de 2016 y el Código Aduanero de la Unión (CAU), actualmente vigente, se puede referenciar en la tabla 6 .

Tabla 6. Resumen de los principales cambios operados entre el CAC y el CAU en relación con los regímenes especiales

\begin{tabular}{ll}
\hline CAC (Código Aduanero Comunitario) & CAU (Código Aduanero de la Unión) \\
\hline \multicolumn{1}{c}{ En vigor hasta mayo de 2016} & En vigor a partir de mayo de 2016 \\
\hline $\begin{array}{l}\text { 1. Concepto y enumeración de destinos } \\
\text { aduaneros }\end{array}$ & No existen como tales \\
\hline $\begin{array}{l}\text { 2. Concepto y enumeración de regímenes } \\
\text { aduaneros económicos }\end{array}$ & $\begin{array}{l}\text { Concepto y enumeración de regímenes } \\
\text { especiales }\end{array}$ \\
\hline 3. Transformación bajo control aduanero & $\begin{array}{l}\text { No existe transformación bajo control aduanero. } \\
\text { Desaparece intención de reexportar en RPA }\end{array}$ \\
\hline
\end{tabular}


CAC (Código Aduanero Comunitario)

En vigor hasta mayo de 2016
CAU (Código Aduanero de la Unión)

En vigor a partir de mayo de 2016

No existe perfeccionamiento ni reintegro

Se denomina destino final y es un régimen

Especial

No existen

6. Intereses compensatorios

Zona Franca como régimen especial

Zona franca siempre cerrada (se eliminan las de tipo 2). No existen depósitos francos (en el caso correspondiente pasan a ser depósitos aduaneros) ${ }^{3}$

Fuente: Arteaga, et. al. (2016, p. 22).

\section{Desempeño de las zonas económicas especiales establecidas en África Subsahariana}

Esta modalidad económica no se utilizó por la mayoría de países africanos sino hasta los años 90 y 2000, a pesar del éxito que tuvieron en los años 70 países como Liberia (1970), Islas Mauricio (1971) y Senegal (1974), como lo demuestran los estudios de Farole (2011) que se representa en la tabla 7.

Tabla 7. Evolución del número de países africanos con presencia de ZEE

\begin{tabular}{llll}
\hline $\begin{array}{c}\text { Década } \\
\text { de } 1970\end{array}$ & $\begin{array}{r}\text { Década } \\
\text { de 1980 }\end{array}$ & \multicolumn{1}{c}{$\begin{array}{c}\text { Década } \\
\text { de } 1990\end{array}$} & $\begin{array}{c}\text { Década } \\
\text { del } 2000\end{array}$ \\
\hline Liberia & Djibouti & $\begin{array}{l}\text { Burundi, Cameroon, Cape Verde, } \\
\text { Equatorial Guinea }\end{array}$ & Gabon, Cambia \\
\hline Senegal & Togo & Ghana, Kenia, Madagascar, Malawi & Mali, South Africa \\
\hline Mauritius & & $\begin{array}{l}\text { Mozambique, Nimibia, } \\
\text { Nigeria, Rwanda }\end{array}$ & Zambia, Eritrea \\
\hline
\end{tabular}

Fuente: Farole (2011, p. 68).

3 Los numerales 7 y 8 son los que involucran directamente a las zonas francas. 
Estudios realizados por el Banco Mundial (2008) afirman que la mayor parte de su gestión es pública, con excepción de Ghana y Kenia donde el desarrollo de estas organizaciones es de orden privado. Normalmente los sectores de la economía de estas ZEE son el textil y los alimentos, además se enfocan en parques industriales y fábricas individuales, todas ellas orientadas a las exportaciones, donde su mercado meta es la Unión Europea y últimamente vienen en aumento las exportaciones a Estados Unidos. La inversión extranjera también proviene de la Unión Europea, aunque en los últimos años han incursionado a este mercado las organizaciones procedentes del continente asiático. En cuanto a la generación de empleo, la fuente proviene de la International Labour Organization (ILO): para el 2006, las ZEE en África y el Océano Índico (Islas Mauricio, Madagascar y Seychelles) generaban más de un millón de empleos (Farole, 2011). En la figura 1 se puede corroborar que la proporción en porcentaje es baja, con apenas un $4 \%$ sobre la escala de medición de las economías emergentes y en desarrollo.

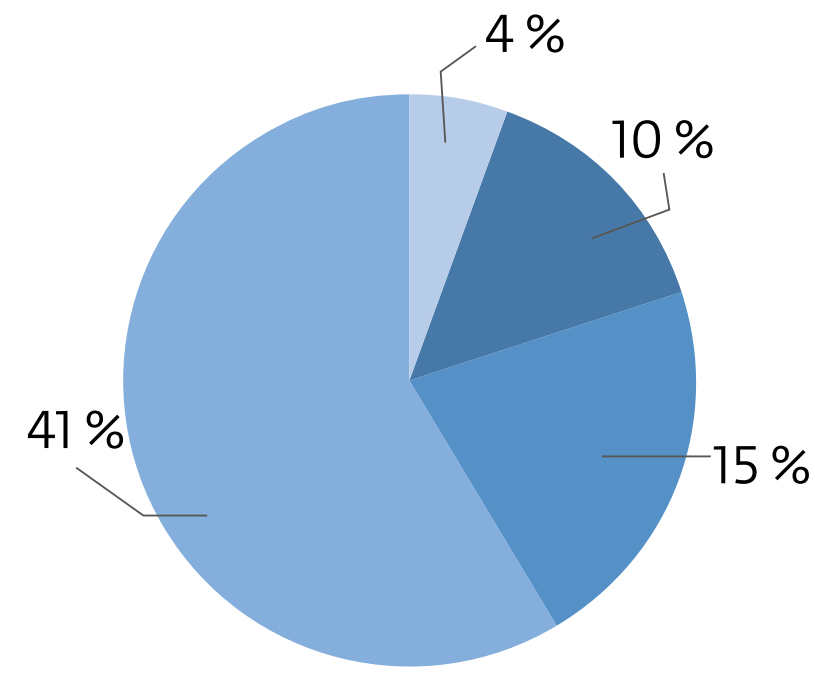
Middle East
Europe Central Asia
East and South Asia
Sub - Saharan Africa

Figura 1. Distribución por regiones de las ZEE para economías emergentes y en desarrollo para el año 2005

Fuente: Farole, (2011, p. 43). 
En los estudios realizados por el Banco Mundial (2008) se ratifica que el éxito en las ZEE es fluctuante. Países como Islas Mauricio, Kenia, Madagascar y Ghana lo han obtenido, mientras que en otros, como Nigeria, Senegal, Malawi, Namibia y Mali, su rendimiento se cataloga como bajo debido a diferentes factores, entre los que se destacan: una mala localización, la falta de un plan estratégico y la gestión inadecuada (debido a que se centran en aquellos sectores donde los países carecen de ventajas competitivas), inestabilidad política, mala aplicación de regulaciones y prácticas operativas, así como la falta de infraestructuras y un conjunto de servicios que acompañen a esta. La competitividad es un factor desequilíbrate para las ZEE africanas, si se compara con los asiáticos y sudamericanos: Ios salarios africanos son, en promedio, más altos comparados con países como Bangladesh y Vietman, mientras que su productividad es menor. Comparados con los Sudamericanos, la mano de obra de las ZEE africanas es más barata pero su productividad es mucho menor (Farole, 2011).

\section{Zonas económicas especiales de Oriente Medio y Norte de África}

En estudios realizados por el Banco Mundial (2008) se describen aquellos países que fueron pioneros en el Oriente Medio en el proceso de desarrollo de las ZEE. La entidad menciona a Jordania, Israel, Siria y Egipto, establecidas en los años 60 y 70 del siglo pasado. Estas zonas, en su mayoría, se establecieron como zonas francas de libre comercio donde predominan las actividades de empaquetado, reempaquetado y las transacciones comerciales, aunque no se descartan algunas dedicadas a la fabricación y transformación de productos tanto en proceso como elaborados. Como ejemplo de estas últimas se puede citar las zonas de Egipto y Jordania que se han dedicado a la industria textil (fabricación).

Por su parte, Emiratos Árabes Unidos ha incursionado con fuerza durante las últimas décadas en este sector. A nivel mundial es reconocida Dubay Multi Commodities Centre por la cantidad de organizaciones que hacen parte de ella y por el volumen de mercancía que mueve. A pesar de todos estos adelantos, 
se considera a la región con muy pocas ZEE, especialmente si se compara con el mercado asiático y suramericano (Mullan, 2014).

\section{Zonas económicas especiales de Europa Occidental}

El concepto de ZEE no es nuevo para la Unión Europea debido al gran desarroIlo del comercio existente en la región durante siglos, bajo la figura de zonas de libre comercio. Son prueba de ello Reino Unido, Italia y Dinamarca (Banco Mundial, 2008).

Hay que tener en cuenta que la transformación de mercancía no comunitaria no es permitida en las zonas francas, a no ser que estén vinculadas al régimen de perfeccionamiento activo que exige la reexportación del artículo resultante, o a la transformación de los productos bajo el control aduanero, en caso de que el destino final del producto sea el territorio aduanero de la comunidad.

Como se mencionó anteriormente, la primera zona franca industrial dedicada a la exportación fue creada en el año de 1959, en el aeropuerto internacional de Shannon, en virtud de lo cual lleva su nombre. Esta zona sirvió de ejemplo para desarrollar otros modelos a nivel mundial, ofreciendo a sus inversores buenos incentivos fiscales, alquiler de instalaciones subvencionadas con todo tipo de servicios y acceso seguro a los mercados europeos. Dentro de la zona operan 120 organizaciones, que en la actualidad dan empleo a 7500 personas (Farole, 2011).

\section{Zonas francas del Este Asiático}

Desde mediados de la década de los 6o, el mundo cambió su enfoque económico de cierre de fronteras a la industrialización, principalmente por el de sustitución de importaciones y estrategias industriales de "gran empuje". La región se caracterizó por adoptar modelos que sirvieran de insumo a 
diferentes ideologías políticas, como le sucedió a China con el rompimiento de la hegemonía comunista para cambiar a ideales capitalistas. Según Farole (2011), las primeras zonas francas conocidas en la región se suscriben en Taiwan (China) donde se desarrolla Kaoshiung en 1965, Nantse en 1969 y el Taichung Zona en 1971. Por su parte, en la India también se desarrolla el modelo con la zona franca de Kandla en 1965, precediéndole la zona de Santacruz en 1973. El fenómeno tuvo eco en otros países de la región como Corea del Sur, que desarrolló su primera zona, Masan, en 1971. Indonesia, Malasia, Filipinas, Tailandia, Singapur y Sri Lanka desarrollaron zonas en este mismo período. Cabe mencionar algunos modelos de éxito que se salen de los parámetros de creación de empleo, como ocurrió en Masan, que apoyaba netamente a la industria local atrayendo a empresas extranjeras para que hicieran parte de industrias domésticas. Al igual que los países anteriormente citados, Malasia desarrolló con gran éxito su primera zona franca en 1972, en la isla de Penang, convirtiéndose en un atractivo principal para las empresas estadounidenses que veían en el mercado de la electrónica una oportunidad grande de comercialización. Al respecto, Farole sostiene lo siguiente:

Las ZFI de Malasia crecieron un 13,3 por ciento al año en los años setenta. En 1995, más de 400 empresas estaban operando en las zonas. En 2003, las zonas empleaban cerca de un millón de trabajadores, un tercio de ellos en segmentos cada vez más creciente en la industria de la electrónica. La industria electrónica de Malasia, creada virtualmente desde la nada dentro de las zonas, ahora produce cerca del 10 por ciento de los Semiconductores del mundo (2011, p. 35).

\section{El modelo chino}

Es importante tratar el modelo chino en un aparte especial por su trayectoria e impacto a la economía, tanto a nivel nacional como internacional, para las zonas económicas especiales. No es fácil cambiar la cultura comunista por unos ideales capitalistas imperantes en los años 70 y 80 del siglo pasado, como ocurrió con China. 
Las primeras zonas se establecieron en el año de 1978 como solución a la reestructuración controlada de toda la economía, a través de la introducción del capitalismo y la inversión extranjera, después de más de 30 años de aislamiento económico y político basados en los ideales del comunismo y cerrado al mundo desde 1949. Como primera medida, el modelo se estableció en las costas de país, tal es el caso de las tres zonas pertenecientes a la provincia de Guangdong y la zona desarrollada en Fujian. Durante los años 80 y 90 del siglo pasado, el proyecto se multiplicó al interior del país, logrando un éxito total en el mundo, al punto de convertirse en el mayor exportador de manufacturas y el principal receptor de inversión extranjera directa entre las economías emergentes.

Estos datos se sustentan en las asombrosas cifras estadísticas mostradas por Farole (2011), quien describe que China, durante el periodo de 1979 a 1995, recibió el $40 \%$ de la inversión extranjera directa para los países en desarrollo, cuyo $90 \%$ se repartió en las zonas costeras. De ese total, las tres zonas de la provincia de Guangdong absorbieron el $50 \%$, lo que equivale a decir que, durante este periodo, estas tres zonas de China se quedaron con el 7,2 \% del volumen total de la inversión extranjera directa para todas las economías emergentes del mundo y el $18 \%$ de la inversión extranjera directa de China.

En la actualidad, China cuenta con más de zoo zonas de diversas concentraciones sectoriales, tipos y tamaños, por ejemplo: parques industriales, comerciales, especializados, de servicios; además está ampliando su rango en modelos globales con"zonas de cooperación económica" para el mundo (Farole, 2011).

\section{Zonas francas en Norte América}

El caso de México, que se cataloga como país norteamericano, se abordará en la sección de la región latinoamericana y del Caribe. Cabe mencionar que Canadá no posee en su economía el modelo de zonas francas, aunque sí se utilizan otros instrumentos parecidos como la reposición en la franquicia arancelaria, los depósitos, sistemas de devolución de derechos, instrumentos del sistema de importación temporal y la admisión temporal (Farole, 2011). 
Estados Unidos cuenta con la figura de zonas de comercio exterior centradas específicamente en el mercado interno, aunque también se adopta a la figura exportadora. Esta información se puede corroborar en el informe 77 del United States Foreing Trade Zones Board, en el que se demuestra que para el año 2015 se importaron hacia las zonas $\$ 414,6$ (miles de millones de dólares) en mercancías, siendo solo exportado a otros países $\$ 84,6$ (mil millones de dólares), lo que demuestra claramente la focalización hacia el mercado interno, inclinándose principalmente hacia los sectores de refinería, equipo informático y de oficina, electrónica y vehículos (tabla 8).

Tabla 8. Resumen estadístico de las transacciones de las zonas de comercio exterior de EEUU del 2011 al 2015

\begin{tabular}{llllll}
\hline Rubro & 2011 & 2012 & 2013 & 2014 & 2015 \\
\hline Mercancía recibida & 604,9 & 723,2 & 835,8 & 798,1 & 659,4 \\
\hline Almacenaje/Distribución & 106,2 & 181,8 & 264,5 & 234,5 & 228 \\
\hline Producción & 534,6 & 550,4 & 571,3 & 563,6 & 431,4 \\
\hline \% de producción & $83 \%$ & $75 \%$ & $68 \%$ & $71 \%$ & $65 \%$ \\
\hline Importaciones & 277 & 303,8 & 290,3 & 288,3 & 244,8 \\
\hline Almacenaje/Distribución & 52,1 & 91,9 & 100,8 & 112,4 & 126,5 \\
\hline Producción & 224,9 & 211,8 & 189,5 & 175,9 & 118,3 \\
\hline Entradas de estado doméstico & 363,8 & 428,5 & 545,5 & 509,7 & 414,6 \\
\hline Almacenaje/Distribución & 54,1 & 89,9 & 163,7 & 122 & 101,5 \\
\hline Producción & 309,7 & 338,6 & 381,8 & 387,7 & 313,1 \\
\hline Ratio de las entradas de estado doméstico & $57 \%$ & $58 \%$ & $65 \%$ & $64 \%$ & $63 \%$ \\
\hline Almacenaje/Distribución & $51 \%$ & $49 \%$ & $62 \%$ & $52 \%$ & $45 \%$ \\
\hline Producción & $58 \%$ & $61 \%$ & $67 \%$ & $69 \%$ & $73 \%$ \\
\hline Exportaciones & 54,3 & 69,9 & 79,5 & 99,2 & 84,6 \\
\hline Almacenaje/Distribución & 12,5 & 16,7 & 18,6 & 32,6 & 25,2 \\
\hline Producción & 41,8 & 53,2 & 60,9 & 66,6 & 59,4 \\
\hline Número de zonas francas aprobadas & 257 & 256 & 257 & 258 & 262 \\
\hline Número de zonas francas activas & 171 & 174 & 177 & 179 & 186 \\
\hline
\end{tabular}

Fuente: Informe 77 del United States Foreing Trade Zones Board. (2015, p. 6). 
Según el mismo informe, hacían parte de la zona 2900 organizaciones que empleaban a 420.000 personas en el año. De igual manera, el valor de los envíos a las zonas totalizó casi 660.000 millones de dólares, en comparación con los 798.000 millones de dólares del año anterior (Informe 77 del United States Foreing Trade Zones Board, 2015).

\section{Zonas francas de América Latina y el Caribe}

Se puede afirmar que las zonas francas no son un fenómeno nuevo para la región, por el contrario, se cuenta con datos históricos que sustentan la teoría sobre algunos países que iniciaron sus transacciones durante o antes de la década de los años 70 del siglo pasado, teniendo como metas la generación de empleo, adquisición de nuevas tecnologías, diversificar sus exportaciones o ser mercados atrayentes para la inversión de capital extranjero (tabla 9). Muchos de estos programas se iniciaron como zonas de libre comercio y fueron apoyadas por el gobierno.

Dentro de la evolución histórica de las zonas francas, vale la pena resaltar los modelos de Puerto Rico y México que fueron trascendentales para la generación y expansión hacia otros países de la región. En 1948, Puerto Rico centró su estrategia en la introducción de programas de industrialización sirviendo de ejemplo para lo que más adelante se denominaron las zonas francas industriales. La operación se llamó “Bootstrap”, y consistió en atraer a las organizaciones estadounidenses para establecer sus operaciones en la isla, con el fin de aprovechar la oportunidad de puerto aduanero libre para los Estados Unidos. Con esta estrategia, Puerto Rico le apuntaba a la exportación, incremento del empleo y dejar de ser país dependiente de una economía monocultural de plantaciones como lo describe Farole (2011).

Farole (2011) también resalta la importancia de las maquiladoras mexicanas surgidas como consecuencia de la culminación del programa "Bracero" en 1964, 
entre USA y México, que dejó a este último con una grave escasez de empleo, sobre todo en las ciudades fronterizas donde el desempleo alcanzó el 50 \%. El nuevo programa permitió a las organizaciones estadounidenses, radicadas en las fronteras del territorio mexicano, obtener abundante y barata mano de obra. Como hasta entonces las normas de inversión y comercialización de México se basaban en la sustitución de importaciones, el nuevo régimen necesitó de cambios específicos, los cuales se centran en los siguientes postulados:

- Permiso para la importación libre de aranceles en territorio mexicano y a 20 kilómetros a la redonda de materiales, componentes y equipo de capital, siempre y cuando el producto se exportara y estos artículos permanecieran representados en bonos mexicanos.

- Las empresas se consideran parte de parques industriales de propiedad privadas administradas por el Nacional Fronterizo (Pronaf) y su representación extranjera no puede exceder el $49 \%$.

Al comienzo, el impacto de las maquiladoras mexicanas no fue tan significativo, aunque más de 200 empresas contrataron a 30.000 personas. Sin embargo, el gobierno mexicano aprobó en los años 70 una serie de actos legislativos, con lo cual se incrementó la cifra en el año 1974 a 455 empresas que contrataron a más de 76.000 personas. Hoy en día la cifra se multiplicó por más de diez veces. A este proyecto se le atribuye ser el artífice del Tratado de América del Norte Ley de Libre Comercio de 1994 (TLCAN).

El impacto en la zona se vio reflejado rápidamente en países como Colombia y República Dominicana, que fueron los primeros adoptantes del proyecto. Colombia abrió sus fronteras con la zona de Barranquilla en el año de 1964; República Dominicana implementó el proyecto de la Romana en 1965 y poco después, en la década de los 70, le siguieron El Salvador, Guatemala, Honduras, Nicaragua y Jamaica. Costa Rica, que en la actualidad es un caso exitoso, implementó su primera zona franca en 1981 (Farole, 2011). 
Para complementar lo anterior, Granados (2003) menciona que estos proyectos tomaron mucha importancia en la región durante la década de los años 80, debido a la necesidad de implementar una nueva estrategia que consistía en la inserción de mercados internacionales y que a su vez se supliera la decadente sustitución de importaciones. Los esfuerzos se centraron en"la apertura económica unilateral, el ingreso al sistema multilateral de comercio, el remozamiento de la integración regional, la negociación de acuerdos de integración sur-sur y sur-norte y el establecimiento de políticas de atracción de inversión extranjera" (2003, p. 79-80), así como en la diversificación de exportaciones a terceros mercados. Actualmente, la gran mayoría funcionan bajo la figura de parques industriales o empresas individuales de zona franca establecidas con capital privado y bajo el modelo de zonas francas de exportaciones. La mayoría de ellas son manufactureras y la mayor parte de su capital es extranjero (Banco Mundial, 2012).

Tabla 9. Introducción a los programas de zonas francas en algunos países centroamericanos y del Caribe

\begin{tabular}{lccc}
\hline Países & $\begin{array}{l}\text { Establecimiento del } \\
\text { primer programa de } \\
\text { Zona }\end{array}$ & $\begin{array}{l}\text { Año del primer } \\
\text { régimen de zona } \\
\text { actual }\end{array}$ & $\begin{array}{c}\text { Numero de } \\
\text { zonas francas } \\
\text { en operación }\end{array}$ \\
\hline El Salvador & 1974 & 1998 & 16 \\
\hline Guatemala & 1973 & 1989 & 24 \\
\hline Honduras & 1977 & 1987 & 24 \\
\hline Nicaragua & 1976 & 2005 & 35 \\
\hline Costa Rica & 1978 & 1990 & 51 \\
\hline República Dominicana & 1969 & 1990 & 14 \\
\hline Panamá & 1948 (Zona Libre Colon) & 1992 (Zonas Francas) & 14 \\
\hline
\end{tabular}

Fuente: Banco Mundial (2012, p. 5).

Según el informe del Banco Mundial (2012), se puede afirmar que en la región imperan tres modelos de zonas francas, a saber: 
1). El que representa aquellas zonas francas que se enfocan en la industrialización y el incremento del valor agregado de bienes y servicios. Lo representan modelos en Costa Rica, República Dominicana y Colombia.

2). Aquellas zonas francas enfocadas a la continua y alta dependencia de la manufactura textil, como sucede en Salvador, Honduras, Guatemala y Nicaragua.

3). Aquellas zonas libres que se han especializado en servicios de logística, distribución de mercancías y servicios en general, como sucede con la zona libre de Colón en Panamá.

Según Rivera (2016), para comienzos del 2016, el total de zonas francas para la región fue de 445 y el número de organizaciones que conformaban dichas zonas era de 10.800, generando 1.700.000 empleos, de los cuales 820.300 correspondieron a empleos directos. Por su parte, las exportaciones correspondientes a las zonas francas de la región alcanzaron la cifra de 27.600 millones de dólares y el valor de las mercancías introducidas alcanzó la cifra de 37.700 millones de dólares. En cuanto al salario recibido por un empleado de zona franca en la región es de USD 1.030, mientras que un salario corriente correspondiente a otras organizaciones está en la región en USD 350. El impacto positivo de las zonas francas en la región también se ve reflejado en el PIB de los países, como por ejemplo en Nicaragua que correspondió al $12 \%$, Costa Rica con el 5.7\%, Ecuador con el 5,2\%, Curazao con el 5,0\%, Uruguay con el 3,5\% y República Dominicana con el $3,2 \%$.

\section{Zonas francas de Colombia}

Como se expresó en apartes anteriores, Colombia y República Dominicana (La Romana, 1965) fueron los primeros adoptantes del modelo de zonas francas libres, después de las experiencias a nivel mundial de Puerto Rico, Irlanda (modelo Shannon, adoptado en 1959) ylas maquilas mexicanas (Farole, 2011). En Colombia, la primera zona franca que se implementó fue la de Barranquilla, en el año 1964. En primera instancia, los proyectos colombianos fueron netamente 
públicos. Con el pasar de los años, la mayoría de zonas francas se fueron privatizando y transformando en parques industriales o comerciales, entre otros que pertenecen a los sectores de la industria, servicios o agroindustria, con un porcentaje de $53 \%, 34 \%$ y $13 \%$, respectivamente (figura 2). De igual forma sucede con el empleo, pues, si se miran las proyecciones del 2009 al 2016, las zonas francas han sido elemento fundamental para su generación al pasar de 28.954 a 62.732 empleos directos y 51.576 empleos indirectos en 2009 , a 164.742 para el año 2016.

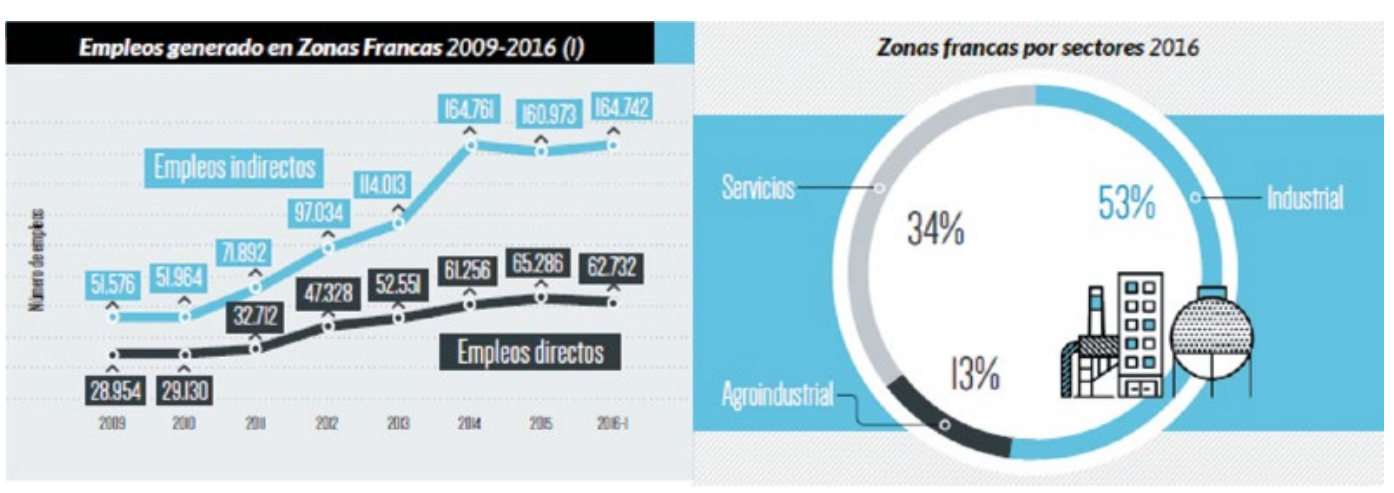

Figura 2. Estadística de empleos generados del 2009 al 2016 y zonas francas por sectores

Fuente: ANDI (septiembre, 2016)

En la actualidad, Colombia es el país latinoamericano con el mayor número de Zonas Francas: cuenta con 38 zonas francas permanentes y 62 zonas francas permanentes especiales. La figura 3 describe la evolución de la cantidad de organizaciones que hacen parte de las 100 zonas francas existente en la actualidad. Allí se puede apreciar que del 2009 al 2016 las organizaciones pertenecientes al sector industrial, y que hacen parte del régimen de zonas francas o parques industriales, van en aumento (de 416 en el 2009, a 697 en el 2016); mientras que las organizaciones pertenecientes al comercio presentan una disminución significativa (de 192 en el 2009, a 120 en el 2016). En cuanto a la inversión acumulada plasmada en millones de dólares, en los periodos del 2010 al 2015 se presenta un importante incremento, llegando a un tope de 19.866 millones de dólares para el año 2015. 
Usuarios de Zonas Francas

2009-2016 (I)

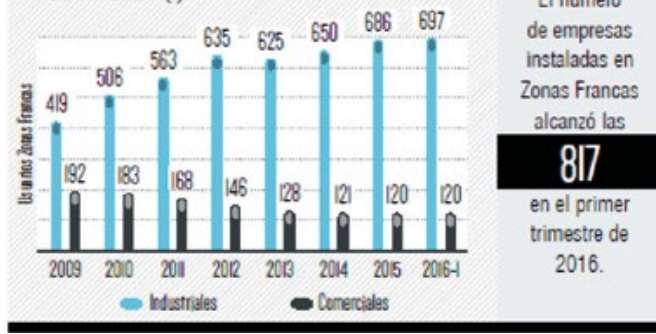

Inversión Acumulada

2010-2015 (Millones de USD)

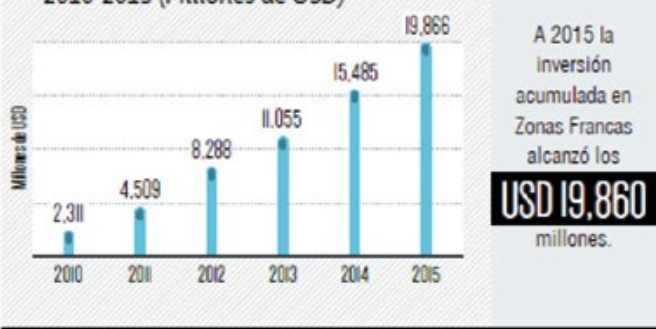

Figura 3. Organizaciones usuarias de zonas francas del 2009 al 2016, inversión acumulada del 2010 al 2015

Fuente: ANDI (septiembre, 2016).

Otras cifras a tener en cuenta son las exportaciones que, según el DANE (2017), para las zonas francas colombianas en el 2016 fueron de USD3.093,1 millones, presentando una variación de 46,7\%. En 2015 la variación fue 1,1 \% y se exportaron USD2.108,8 millones. En cuanto a las importaciones totales de mercancías hacia las zonas francas colombianas, para el año 2016 fueron de USD2.041,1, presentando una variaron de $-14,3 \%$. Si se comparan con el 2015 , estas estuvieron en el orden de USD2.380,4 millones y la variación fue -14,6\%. Si se compara la balanza comercial, en el 2016 las zonas francas colombianas registraron un superávit de USD1.120,9 millones y en 2015 un déficit de USD208,6 millones.

\section{Aspectos normativos}

Como lo ratifican Ramos y Rodríguez (2012), el régimen de zonas francas en Colombia data del año 1958, cuando surge la zona de Barranquilla como un mecanismo facilitador del comercio y la importación de insumos para la producción de bienes para los mercados internacionales y el consumo nacional, cuando la estrategia económica del país se centró en la sustitución de importaciones seguida por muchos países de la región y del mundo. La Ley 109, promulgada en 1985, establece a estas entidades como organismos públicos de orden nacional enfocadas en los siguientes objetivos: fomento del comercio exterior, generación de empleo y divisas, y promoción del desarrollo regional. 
Otro factor a tener en cuenta en este marco es el proceso de privatización de las zonas francas, suscitado en el año 1991. Para el año de 1996 se establece el decreto 2233, que redefine las zonas francas industriales de bienes y servicios como aquellas "áreas geográficas dentro de las cuales se debían desarrollar actividades económicas dirigidas principalmente a la producción de bienes y servicios para los mercados externos" (Ramos y Rodríguez, 2012. p. 5).

En el año 2005 surge la Ley 1004, que se enfoca en revisar el concepto de zona franca implementando la nueva definición: "área geográfica delimitada dentro del territorio nacional, en donde se desarrollan actividades industriales de bienes y de servicios, o actividades comerciales, bajo una normatividad especial en materia tributaria, aduanera y de comercio exterior". Esta misma ley establece que el fin de las zonas francas es la "creación de empleo, la captación de nuevas inversiones de capital, el desarrollo competitivo de las regiones y de los procesos industriales, la generación de economías de escala y la simplificación de procedimientos de comercio". (Ministerio de Comercio Industria y Turismo, 2013).

\section{Marco normativo de las zonas francas en Colombia}

- Decreto 2685 de 1999 (Estatuto Aduanero), Títulos IX y XV, modificado por los Decretos 383 de 2007, 4051 de 2007, 780 de 2008, 4285 de 2009, 4584 de 2009,1769 de 2010.

- Resolución de la Comisión Intersectorial de Zonas Francas or del 3 de diciembre de 2007.

- Resolución de la DIAN 4240 de 2000, Títulos II, IV, VIII, IX, modificada por las Resoluciones 5532 de 2008, 7941 de 2008, 9254 de 2008, 830 de 2008, 1867 de2009, 546 de 2010, 7310 de 2010, 8571 de 2010 y 11375 de 2010. (Ministerio de comercio Industria y Turismo, 2013). 


\section{Características de las zonas francas (Ley 1004 de 2005, art. $1^{\circ}$ )}

- Área geográfica delimitada dentro del territorio nacional para desarrollar actividades industriales de bienes y de servicios, o actividades comerciales.

- Con una normatividad especial tributaria, aduanera y de comercio exterior. Las mercancías ingresadas a zona franca se consideran fuera del territorio aduanero nacional (Ministerio de comercio Industria y Turismo, 2013).

- Ser instrumento para la creación de empleo y para la captación de nuevas inversiones de capital.

- Ser un polo de desarrollo que promueva la competitividad en las regiones donde se establezca.

- Desarrollar procesos industriales altamente productivos y competitivos, bajo los conceptos de seguridad, transparencia, tecnología, producción limpia y buenas prácticas empresariales.

- Promover la generación de economías de escala.

- Simplificar los procedimientos del comercio de bienes y servicios para facilitar su venta.

\section{Beneficios legales}

- Tarifa única del impuesto sobre la renta del $15 \%$.

- No se causan ni pagan tributos aduaneros (IVA y arancel) en las importaciones a zona franca.

- Posibilidad de exportación desde zona franca a terceros países y al mercado nacional.

- Las exportaciones desde zona franca se benefician de acuerdos comerciales internacionales.

- Las mercancías de origen extranjero introducidas a la zona franca podrán permanecer en ellas indefinidamente. 


\section{Requisitos para pertenecer a una zona franca}

- Crear una nueva compañía en Colombia.

- Presentar un plan de negocio ante el usuario operador, quien le dará la calificación como usuario.

- Cumplir con los siguientes requisitos que se describen en la tabla 10:

Tabla 10. Capital de inversión para ingresar a una zona franca

\begin{tabular}{|c|c|c|}
\hline Monto activos de nueva empresa & $\begin{array}{l}\text { Compromiso } \\
\text { de inversión }\end{array}$ & $\begin{array}{l}\text { Compromiso } \\
\text { generación de empleo }\end{array}$ \\
\hline Inversión < 500 SMMLV4 Aprox. USD 148.000 & No hay requisitos & No hay requisitos \\
\hline 500 SMMLV < Inversión < 5.000 SMMLV & \multirow{2}{*}{ No hay requisitos } & \multirow{2}{*}{$\begin{array}{l}20 \text { empleos a la puesta en } \\
\text { marcha del proyecto }\end{array}$} \\
\hline USD 148.000 < inversión < USD1.5 M aprox. & & \\
\hline 5.001 SMMLV < Inversión < 30.000 SMMLV & $\begin{array}{l}\text { Nueva inversión } \\
\text { de } 5.000 \text { SMMLV }\end{array}$ & \multirow{2}{*}{$\begin{array}{l}30 \text { empleos a la puesta en } \\
\text { marcha del proyecto }\end{array}$} \\
\hline USD 1.5 M < inversión < USD9 M aprox. & (USD 1.5M) & \\
\hline Inversión > 30.000 SMMLV & $\begin{array}{l}\text { Nueva inversión } \\
\text { de } 11.500 \text { SMMLV }\end{array}$ & \multirow{2}{*}{$\begin{array}{l}50 \text { empleos a la puesta } \\
\text { en marcha del proyecto }\end{array}$} \\
\hline Inversión > USD 9 M aprox. & (USD $3.4 \mathrm{M})$ & \\
\hline
\end{tabular}

Fuente: Grupo Zona Franca Bogotá ZFB, (2015).

\section{Tipos de zonas francas}

Con el decreto 383 de 2007 se establecen tres tipos de zonas francas: Ias permanentes, las permanentes especiales o "uniempresariales" y las transitorias. El decreto define a las zonas francas permanentes o multiusuarios como un "área

4 SMMLV. Esta sigla significa salario mínimo legal vigente colombiano. En la actualidad, un salario mínimo legal vigente colombiano equivale a $\$ 737.717$ pesos colombianos. 
geográfica delimitada dentro del territorio nacional con normatividad especial y donde se desarrollan actividades industriales o comerciales de bienes y servicios". De la misma manera, establece que una sola empresa puede obtener las ventajas de zona franca permanente especial o uniempresarial instalándose en cualquier lugar de Colombia, siempre y cuando cumpla con los requisitos de inversión y empleo que establece la norma y que los proyectos sean de alto impacto económico y social para el país. Con el decreto se establece para las zonas francas permanentes, montos mínimos de inversión y de creación de empleo. Para la conformación de zonas francas uniempresariales se elimina el requisito de área mínima de 20 hectáreas. La figura de las zonas francas transitorias queda establecida por zonas que son declaradas de manera temporal en lugares donde se celebren ferias, exposiciones, congresos y seminarios de carácter internacional y que revistan importancia para la economía y el comercio internacional del país. En este mismo año y con el decreto 4051 se establece la opción para que las organizaciones que desarrollen un proyecto surjan como zonas francas permanentes especiales, siempre y cuando la nueva inversión sea por USD178,2 millones o más, su patrimonio líquido sea superior a USD38,6 millones y puedan duplicar su renta gravable. La tabla 11 describe las principales zonas francas de Colombia, resaltando sus principales características.

Tabla 11. Principales zonas francas aprobadas y en funcionamiento en Colombia

\begin{tabular}{|c|c|}
\hline $\begin{array}{l}\text { Nombre / } \\
\text { Ubicación }\end{array}$ & Características \\
\hline \multirow{4}{*}{$\begin{array}{c}\text { Zona Franca } \\
\text { Tayrona, Santa } \\
\text { Marta }\end{array}$} & - Aprobada mediante Resolución No. 4335 del 19 de mayo de 2008 \\
\hline & - Inversión de $\$ 53.482$ millones \\
\hline & - Genera 31 empleos directos y 1.320 empleos Indirectos \\
\hline & - Cuenta con 100.16 hectáreas \\
\hline \multirow{4}{*}{$\begin{array}{l}\text { Zona Franca } \\
\text { del Pacífico }\end{array}$} & - Aprobada mediante Resolución No. 1035 del 26 de agosto de 1993. \\
\hline & - Inversión de \$1.238 millones \\
\hline & - Genera 1.520 empleos directos y 1.120 empleos indirectos \\
\hline & - Cuenta con 5.490 hectáreas. \\
\hline
\end{tabular}


Nombre /

Ubicación

\section{Características}

Fue constituida como zona franca el 12 de marzo de 1993

Zona Franca de Rionegro

- Se aprobó su ampliación mediante Resolución No. 1125 del 1 de febrero de 2008

- Zona franca permanente con destinación industrial

Aprobada mediante Resolución No. 6840 del 15 de julio de 2010

- Zona franca permanente con destinación industrial

Zona Franca Internacional de Pereira

- Inversión de \$34.609 millones

- Genera 80 empleos directos y 20 indirectos

- Cuenta con 27.30 hectáreas

- Aprobada mediante Resolución No. 12560 del 25 de octubre de 2007

- Zona Franca Permanente con destinación industrial para la construcción

Zona Franca

La Cayena

- Inversión de \$57.354 millones

- Genera 429 empleos directos y 820 indirectos

- Cuenta con 112.50 hectáreas.

Zona Franca

- Aprobada mediante Resolución No. 751 del 3 de julio de 1996

Eje Cafetero

- Zona franca permanente con destinación industrial

Aprobada mediante Resolución No. 012842 del 22 de noviembre de 2009

- Zona franca permanente con destinación industrial

Zona Franca

Santander

- Inversión de \$28.791 millones

- Genera 24 empleos directos

- Cuenta con 29.43 hectáreas

Aprobada mediante Resolución No. 4966 del 25 de mayo de 2010

- Zona franca permanente especial de servicios de salud, ubicada en

Zona Franca

Salud Fosunab Floridablanca, Santander

- Inversión de $\$ 50.560$ millones

- Genera 198 empleos directos

- Cuenta con 1.60 hectáreas

Su ampliación fue aprobada mediante Resolución No. 13022 del 2 de noviembre de 2007

Zona Franca Bogotá

- Zona franca permanente 


\begin{tabular}{|c|c|}
\hline $\begin{array}{l}\text { Nombre / } \\
\text { Ubicación }\end{array}$ & Características \\
\hline \multirow{3}{*}{$\begin{array}{l}\text { Zona Franca } \\
\text { Manizales }\end{array}$} & Aprobada mediante Resolución No. 3458 del 18 de marzo de 2011 \\
\hline & - Inversión de $\$ 30.230$ millones \\
\hline & - Genera 24 empleos directos \\
\hline \multirow{3}{*}{$\begin{array}{l}\text { Zona Franca } \\
\text { Palmaseca }\end{array}$} & - Se constituyó como sociedad en julio de 1970 \\
\hline & $\begin{array}{l}\text { - Fue declarada como zona franca privada mediante } \\
\text { Resolución No. } 835 \text { del } 2 \text { de junio de } 1994\end{array}$ \\
\hline & - Zona franca permanente \\
\hline \multirow{5}{*}{$\begin{array}{l}\text { Zona Franca } \\
\text { Econtac Col S.A.S }\end{array}$} & Aprobada mediante Resolución No. No.14072 del 24 de diciembre de 2009 \\
\hline & $\begin{array}{l}\text { - Zona franca permanente especial de servicios } \\
\text { de call center ubicada en Manizales }\end{array}$ \\
\hline & - Inversión de \$5.182 millones \\
\hline & - Genera 560 empleos directos \\
\hline & - Cuenta con 0.35 hectáreas \\
\hline \multirow{5}{*}{$\begin{array}{l}\text { Zona Franca } \\
\text { Pepsico }\end{array}$} & $\begin{array}{l}\text { Aprobada mediante Resolución No.6748 } \\
\text { del } 28 \text { de julio de } 2008\end{array}$ \\
\hline & $\begin{array}{l}\text { - Zona franca permanente especial de alimentos ubicada en Funza, } \\
\text { Cundinamarca }\end{array}$ \\
\hline & - Inversión de $\$ 69.959$ millones \\
\hline & - Genera 220 empleos directos \\
\hline & - Cuenta con 5.27 hectáreas \\
\hline \multirow{3}{*}{$\begin{array}{l}\text { Zona Franca } \\
\text { de Barranquilla }\end{array}$} & Pionera del régimen franco en Colombia \\
\hline & $\begin{array}{l}\text { Cuenta con un sistema integrado de gestión certificado bajo los } \\
\text { estándares de las Normas ISO } 9001 \text { (versión 2008) y BASC (versión 2012) }\end{array}$ \\
\hline & $\begin{array}{l}\text { En la Zona Franca de Barranquilla opera } 15 \text { zonas francas en el país, } \\
\text { que suman } 4.522 .593,37 \mathrm{~m}^{2}\end{array}$ \\
\hline \multirow{5}{*}{$\begin{array}{l}\text { Zona Franca } \\
\text { Gyplac }\end{array}$} & $\begin{array}{l}\text { Aprobada mediante Resolución No.293 } \\
\text { del } 14 \text { de enero de } 2008\end{array}$ \\
\hline & $\begin{array}{l}\text { - Zona franca permanente especial de placas de yeso de cartón, } \\
\text { ubicada en Cartagena Mamonal, Bolívar }\end{array}$ \\
\hline & - Inversión de $\$ 71.760$ millones \\
\hline & - Genera 150 empleos directos y 250 indirectos \\
\hline & - Cuenta con 12 hectáreas \\
\hline
\end{tabular}

Fuente: elaboración propia con base en datos suministrados por el Ministerio de Comercio Industria y Turismo, (2013, pp. 24-30) y Pro Colombia, Directorio de las Zonas Francas (pp. 9-109). 


\section{Tipos de usuarios de las zonas francas}

Según el decreto 4051 del 23 de octubre del 2007 del Ministerio de Hacienda y Crédito Público, existen cuatro tipos de usuarios para las zonas francas: el usuario operador, el usuario industrial de bienes, el usuario industrial de servicios y el usuario comercial, quienes, a su vez, están regulados por la Dirección de Impuestos y Aduanas Nacionales (DIAN) para el cumplimento de todas sus obligaciones.

Se cataloga como usuario operador a la persona jurídica que esté autorizada para dirigir, administrar, supervisar, promocionar y desarrollar una o varias zonas francas, así como para calificar a sus usuarios. Por lo tanto, es quien controla las operaciones de comercio exterior, promueve el ingreso de nuevas compañías al parque industrial, fomentando su desarrollo al hacer las inversiones necesarias, al igual que las que establece el gobierno para su expansión.

Un usuario industrial de bienes es una persona jurídica que se encuentra instalado en una o varias zonas francas dedicadas a producir, ensamblar o transformar bienes, mediante procesos de materias primas o productos semielaborados, lo que quiere decir que estas organizaciones se dedican a la compra de materia prima, ya sea en el extranjero o en el territorio nacional, para transformarla dentro de la zona franca en productos elaborados o semielaborados y venderlos dentro del país o en el extranjero.

Por su parte, el usuario industrial de servicios está dedicado a prestar un servicio dentro de la zona franca, tal como lo hace un call center o un data center, una clínica o cualquier otra organización que posea esta misión. Por lo tanto, se concibe como una persona jurídica dedicada a desarrollar exclusivamente en una o varias zonas francas las siguientes tareas:

- Logística, transporte, manipulación, distribución, empaque, reempaque, envase, etiquetado o clasificación

- Telecomunicaciones, sistemas de tecnología de la información para captura, procesamiento, almacenamiento y transmisión de datos, y organización, gestión u operación de bases de datos 
- Investigación científica y tecnológica

- Asistencia médica, odontológica y en general de salud

- Turismo

- Reparación, limpieza o pruebas de calidad de bienes

- Soporte técnico, mantenimiento y reparación de equipos, naves, aeronaves o maquinaria

- Auditoría, administración, corretaje, consultoría o similares.

El usuario comercial lo conforma una organización jurídica autorizada para desarrollar actividades de mercadeo, comercialización, almacenamiento o conservación de bienes en una o varias zonas francas; por lo tanto, estas entidades pueden comprar o vender bienes o almacenar mercancías a terceros. A esta clase de usuarios solo se les exonera de los incentivos aduaneros (IVA y arancel) hasta cuando la mercancía salga hacia Colombia, mientras tanto quedan en una extraterritorialidad aduanera para efecto de las importaciones y exportaciones. Todos estos usuarios hacen parte de las zonas francas anteriormente descritas y distribuidos entre las principales industrias de la economía colombiana.

\section{Hallazgos y proposiciones}

Con respecto a las zonas francas a nivel mundial, el capítulo induce a pensar que el objetivo que persigue cada uno de los países o regiones para estas entidades no es el mismo, sino que depende de sus políticas de desarrollo. Por ejemplo, para la economía norteamericana se busca que las zonas francas sean un sustento local, más que un elemento exportador fuerte. En Europa se busca que las zonas francas suplan las necesidades de la UE. En parte del Oriente Medio, África y Latinoamérica, se ve a las zonas francas como aquellos instrumentos capaces de incentivar la generación de empleo, la atracción de inversión extranjera, la transferencia de tecnología, la diversificación productiva, la ampliación de la oferta exportable y la mejora en las modalidades de inserción internacional. 
En ese orden de ideas, las zonas francas son claves para el desarrollo de la nación porque dentro de este sistema cumplen la tarea de ser instrumentos efectivos para atraer inversiones nacionales y extranjeras, con el fin de lograr un impacto positivo en la inversión y el desarrollo productivo y social de las regiones del país.

Teniendo en cuenta que la competitividad y la innovación son parte activa de las organizaciones, uno de los objetivos del Plan Nacional de Desarrollo 2014-2018 para Colombia, se centra en "incrementar la productividad de las empresas colombinas a partir de la sofisticación y diversificación del aparato productivo" (p. 109). Para cumplir con este objetivo, el gobierno nacional centró su atención en desarrollar las siguientes estrategias:

- Internacionalizar los sectores productivos de bienes y servicios

- Fortalecer las capacidades tecnológicas de las empresas

- Racionalizar la regulación para la competitividad empresarial

- Promover el desarrollo regional sostenible

- Profundizar el financiamiento y la formalización empresarial

- Incentivar el desarrollo de una economía naranja

- Hacer los ajustes institucionales requeridos.

Con miras a desarrollar la primera estrategia, que consiste en "internacionalizar los sectores productivos de bienes y servicios", se debe cumplir con la tarea de incrementar las exportaciones. Para esto, los componentes a desarrollar se enfocan en aumentar la admisibilidad en el exterior de los productos y servicios nacionales, fortalecer las capacidades metrológicas, incrementar los ingresos de las cuentas de viajes y transporte de la balanza de pagos, insertarse en cadenas globales de valor, fortalecer la competitividad de las zonas francas y evaluar la política arancelaria, contar con un sistema de aduanas más eficiente para apoyar el comercio internacional y brindar información relevante y acompañamiento técnico a los exportadores de servicios.

Revisando la misión de las zonas francas en nuestro medio durante los últimos diez años, se llega a la conclusión que su gestión ha sido muy volátil y que, si 
bien del año 2010 en adelante su gestión ha aumentado significativamente en cuanto a las exportaciones, se puede apreciar que las importaciones de igual manera han aumentado, hasta el punto en que, en los años 2009, 2014 y 2015, la balanza comercial fue desfavorable para el país (tabla 12).

Tabla 12. Balanza comercial de las zonas francas colombianas 2008-2017

\begin{tabular}{|c|c|c|c|}
\hline & Exportaciones & Importaciones & Balanza comercial \\
\hline Año & $\begin{array}{l}\text { Miles de dólares } \\
\text { FOB }\end{array}$ & $\begin{array}{l}\text { Miles de dólares } \\
\text { FOB }\end{array}$ & $\begin{array}{l}\text { Miles de dólares } \\
\text { FOB }\end{array}$ \\
\hline Total 2008 & 1.112 .033 & 1.111 .599 & 434 \\
\hline Total 2009 & 721.915 & 864.540 & -142.625 \\
\hline Total 2010 & 2.042 .206 & 1.417 .808 & 624.398 \\
\hline Total 2011 & 3.240 .430 & 2.227 .395 & 1.013 .035 \\
\hline Total 2012 & 3.319 .203 & 2.997 .834 & 321.369 \\
\hline Total 2013 & 3.393 .604 & 2.467 .685 & 925.919 \\
\hline Total 2014 & 2.085 .060 & 2.731 .540 & -646.480 \\
\hline Total 2015 & 2.108 .804 & 2.317 .414 & -208.610 \\
\hline Total 2016 & 3.093 .147 & 1.970 .218 & 1.122 .929 \\
\hline Total 2017 & 2.252 .675 & 2.060 .222 & 192.453 \\
\hline $\begin{array}{l}\text { Gran Total durante } \\
\text { los diez años }\end{array}$ & 23.369.077 & 20.166 .255 & 3.202 .822 \\
\hline
\end{tabular}

Fuente: elaboración propia a partir de datos suministrados por el DANE (2018)

Es importante resaltar que, a pesar de los tres años desfavorables para Colombia, la mayoría de los años el resultado fue positivo, y si se suma la trayectoria de los mismos, la balanza es favorable para nuestro país. Así, se corrobora el nivel de importancia de las zonas francas para el comercio exterior colombiano, pues aporta no solo en el ámbito económico sino también en el social, ya que la dinámica de las zonas francas en los últimos 20 años ha tomado una senda de transformaciones y nuevas significaciones en pro de incentivar la generación de empleo, la atracción de inversión extranjera, la transferencia de tecnología, la diversificación productiva, la ampliación de la oferta exportable y la mejora en las modalidades de inserción internacional. 
Además, son entidades que fomentan el desarrollo para las regiones y, como se describió anteriormente, cumplen un papel fundamental para el alcance de las estrategias y metas propuestas en el Plan Nacional de Desarrollo 2014-2018.

\section{Conclusiones}

El rol que desempeñan las zonas francas en la economía mundial es importante porque son los principales entes de desarrollo económico para cada una de las regiones. Esto último, debido a que generan empleo y fomentan las exportaciones, obteniendo como resultado balanzas comerciales favorables para algunos países, como se describió a lo largo de la investigación.

El recorrido por cada una de las regiones induce a pensar que en algunas de ellas el proyecto es favorable, mientras que en otras no lo son. Lo que demuestra que los recursos con que se cuente para desarrollar los proyectos son fundamentales para el logro de las metas. Además, estos proyectos deben estar interconectados con los planes de desarrollo de cada una de las economías para que cumplan la verdadera función.

Queda claro que la función que cumplen las zonas francas no es la misma en la economía mundial: en Asia algunas de ellas están enfocadas en las exportaciones, en Europa y Norteamérica el rol principal es la cobertura del mercado local y para Latinoamérica su rol se enfoca en el desarrollo de las regiones, aumento de las exportaciones y generación de empleo. 


\section{Referencias}

ANDI. (2016). Cámara de usuarios de zonas francas de la ANDI. Estudios y estadísticas. Disponible en http://www.andi.com.co/czf/Paginas/EstudiosyEstadisticas.aspx [consultado el 14 de enero de 2017].

Arteaga, J. y Martínez, X. (2003). Las zonas francas en España. Delimitación del concepto y perspectivas de futuro. Boletín ICE Económico, núm. 2758. pp. 1001-1008.

Arteaga, J., Ferrer, P., Miranda, M. y Riveras, J. (2016). Estudio y análisis de zonas económicas especiales. Propuesta de mejora para las zonas francas españolas actuales. Revista Empresa y Humanismo, XIX(2), 7-50.

Banco Mundial. (2008). Special Economic Zones, Performance, Lessons Learned, and Implications for Zones Development. Washington. EEUU: Banco Mundial.

Banco Mundial. (2012). Infraestructura para desarrollar las exportaciones: Zonas económicas especiales, innovación y sistemas de calidad. En Desarrollando el potencial exportador de América Central. Disponible en http://documents. worldbank.org/curated/en/367031468342536103/Zonas-francas-industriales [consultado el 12 de enero de 2017].

Boyenge, J. P.S. (2007). Base de datos de la OIT sobre las zonas francas de exportación, revisada. Ginebra: Organización Internacional de Trabajo.

CONPES. (2016). Documento CONPES No. 3866. Política Nacional de Desarrollo Productivo. Consejo Nacional de Política Económica y Social. Bogotá, D.C., Colombia: Departamento Nacional de Planeación.

Consejo Privado de Competitividad. (2007). A dónde queremos llegar: Visión 2032 y principales estrategias. Disponible en http://www.compite.com.co/site/wp-content/ uploads/informes/2007-2008/05-CAPITULO2.pdf [consultado el 13 de junio de 2016]. P.12. 
Consejo Nacional de Competitividad. (2016). Índice Global de Innovación. (s.d.).

Departamento Administrativo Nacional de Estadística - DANE. (2017). Sección:

Estadísticas por tema: Zonas Francas - ZF. Disponible en https://www.dane.gov.co/ index.php/estadisticas-por-tema/comercio-internacional/zonas-francas [consultado el 22 de marzo de 2017].

Departamento Administrativo Nacional de Estadística - DANE. (2018). Sección:

Estadísticas por tema: Zonas Francas - ZF. Balanza Comercial Mensual. Disponible en https://www.dane.gov.co/index.php/estadisticas-por-tema/comerciointernacional/zonas-francas [consultado el 22 de marzo de 2017].

Farole, T. (2011), Special Economic Zones in Africa: Comparing Performance and Learning from Global Experience. Washington: Banco Mundial.

FIAS (2008). Special Economic Zones. Perfomance, lessons, learned and implications for zone development, núm. 45869, pp. 5-58. The Word Bank Group.

Foro Económico Mundial (2017-2018). The Global Competitiveness Report. P. 13.

Foro Económico Mundial (2016-2017). The Global Competitiveness Report.

Granados, J y Ramos, A. (2012). Banco Interamericano de Desarrollo - BID. Zonas Francas, comercio y desarrollo en América Latina y el Caribe. Metodología de análisis costo-beneficio de los regímenes de zona franca en América Latina y el Caribe. pp. 47-121. s.d.

Granados, J. (2003). Export processing zones and the other special regimes in the context of multilateral and regional trade negotiations. Buenos Aires: Banco Interamericano de Desarrollo.

Igartua, J. (2009). Gestión de la innovación en la empresa vasca. Contribución de las herramientas de gestión de la innovación. [Tesis doctoral]. España: Universidad Politécnica de Valencia. 
Informe Nacional de Competitividad. (2016). Consejo Privado de Competitividad. Bogotá D.C. - Colombia.

Ministerio de Comercio, Industria y Turismo. (2013). Sección: Estadísticas por tema: Zonas Francas - ZF. Disponible en http://www.mincit.gov.co/documentos/326/2013 [consultado el 15 de marzo de 2018].

Mullan, C. (2014). "Global Cities of the Future 2014/15: the winners", FDI intelligence. Disponible en http://www.fdiintelligence.com/ [consultado el 4 de enero de 2016].

Pakdeenurit, P., Suthikarnnarunai, N. y Rattanawong,W. (2014). "Special Economic Zone: Facts, Roles, and Opportunities of In vestment". Proceedings of the International MultiConference of Engineers and Computer Scientists, Hong Kong.

Plan Nacional de Desarrollo 2014-2018. (2015). Artículo 1 y 3: Objetivo y Pilares del Plan Nacional de Desarrollo. Disponible en https://colaboracion.dnp.gov.co/CDT/Prensa/ ArticuladoVF.pdf [consultado el 13 de septiembre de 2017].

Pro Colombia. (2015). Sección: Directorio: Zonas Francas - ZF. Disponible en http:// www.procolombia.co/directorio-zonas-francas [consultado el 16 de marzo de 2018].

Ramos, J. y Rodríguez, K. (2012). Aspectos normativos. Boletín Banco de la República. Zonas francas en Colombia: Beneficios tributarios en el impuesto de renta. Bogotá, D.C., Colombia: Banco de La República.

Rivera, J. (2016). Informe Estadístico Zonas Francas de América Latina y el Caribe. Revista de la Asociación de Zonas Francas de Las Américas - AZFA. Disponible en http://www.asociacionzonasfrancas.org/es/directorio-zf/paises [consultado el 12 de enero de 2017].

Schwab, K. (edit.). (2017). Reporte Global de Competitividad. Disponible en http://www3.weforum.org/docs/GCR2017-2018/05FullReport/ TheGlobalCompetitivenessReport2017\%E2\%80\%932018.pdf). 
The Economist. (2015). Political priority, economic gamble. Disponible en http://www. economist.com/news/finance-and-economics/21647630-freetrade-zones-are-morepopular-everwith-politicians-if-not [consultado el 10 de septiembre de 2017].

United States Foreing Trade Zones Board. (2015). 64 ${ }^{\text {Th }}$ Annual Report of the Foreign Trade Zones Board to the Congress of the United States. Disponible en http:// enforcement.trade.gov/ftzpage/annual-report.html [consultado el 15 de febrero de 2017].

Zeng, D. (2010). Building Engines for Growth and Competitiveness in China, Experience with Special Economic Zones and Industrial Cluster. The International Bank for Reconstruction and Development/The World Bank. Washington. EEUU. 
